\title{
REGLA DE PRODUCTIVIDAD Y SEÑOREAJE: UNA CRÍTICA AL OBJETIVO DE ESTABILIZACIÓN DE PRECIOS*
}

\author{
JUAN CASTAÑEDA FERNÁNDEZ**
}

Resumen: Con este trabajo hemos actualizado la regla de estabilización de la renta nominal propuesta por Hayek en 1928 como criterio de emisión válido para los bancos centrales en la actualidad. A partir de su aplicación, la estabilidad de precios deja de ser el objetivo de la política monetaria, permitiéndose en su lugar movimientos de precios a lo largo del tiempo como consecuencia natural de variaciones en las condiciones productivas de la economía, en presencia de mercados potencialmente abiertos a la competencia. Con ello estaremos en condiciones de diferenciar la respuesta monetaria óptima del banco central ante distintos tipos de deflación.

Palabras clave: Regla de productividad de Hayek, estabilización de precios, política monetaria neutral, equilibrio monetario.

Abstract: The aim of the paper is to propose a new version of the productivity norm proposed by Hayek in 1928, as a feasible way to develop monetary policy by actual central banks. With this proposal,

* Quiero agradecer la ayuda que me ha prestado el profesor P. Schwartz Girón como director de la tesis doctoral de la que se extrae este trabajo. Sus lecturas propuestas y, sobre todo, las conversaciones mantenidas en el proceso de elaboración de la tesis doctoral me han ido enseñando a cuestionarme la validez de muchos de los modelos teóricos que aún impregnan el cuerpo central de la formación académica como economista. En este sentido, el paso a una perspectiva de análisis de la política monetaria verdaderamente dinámica y de mercado es más arriesgado y complicado, si bien infinitamente más satisfactorio. Gracias.

** Departamento de Economía Aplicada y Gestión Pública, Facultad de Ciencias Económicas y Empresariales, UNED.

Procesos de Mercado: Revista Europea de Economía Política Vol. II, n. ${ }^{\circ}$ 1, Primavera 2005, pp. 53 a 103 
we are able both to review the convenience of the stability price objective adopted by most central banks and to permit price variations according to the evolution of productivity in increasingly open and competitive markets. By using a nominal income objective, central banks can distinguish, for example, between unwelcome monetary deflations and falling prices brought about by increases in productivity. With this objective, the degree of competition and of openness of an economy can also be taken into account by central bankers.

Key words: Hayek's productivity norm, price stability, neutral monetary policy, monetary equilibrium.

Clasificación JEL: E3, E52.

\section{INTRODUCCIÓN: \\ EL CAMBIO DE NATURALEZA \\ DE LOS BANCOS CENTRALES}

Tras el anuncio de abandono del régimen de convertibilidad del patrón oro, que había regulado y caracterizado durante más de un siglo las emisiones del Banco de Inglaterra, J.M. Keynes vislumbra ${ }^{1}$, ya en 1931, las nuevas posibilidades emanadas de un sistema de emisión libre o no restringido como herramienta de la política económica. Se elimina un sistema de regulación de las emisiones del banco central, característico de una era en la que se consideraba al banco emisor del patrón monetario de la economía esencialmente como un banco, y se inaugura una nueva, caracterizada por la posibilidad de determinación libre

1 «Hay pocos ingleses que no se alegren de la ruptura de nuestras cadenas doradas. Sentimos que tenemos por fin las manos libres para hacer lo que es sensato. Ha pasado la fase romántica y podemos empezar a discutir con realismo cuál es la mejor política» (J.M. Keynes, 1931, p. 249). Esta cita recoge la posición crítica de Keynes respecto a la vuelta al patrón oro por parte de Inglaterra que iniciara en el Breve Tratado sobre la Reforma Monetaria, publicado en 1923. 
de la cantidad de liquidez en circulación. Con ello, las emisiones del banco central pasan a ser consideradas plenamente como una variable más, de las controladas por el sector público, al servicio de los objetivos planteados por éste en cada momento. De esta forma, bajo la poderosa influencia de la doctrina difundida por J.M. Keynes en el periodo de entreguerras, así como de sus interpretaciones posteriores, pierden gran parte de su importancia original aquellas funciones del banco central que lo caracterizan como una institución financiera que presta una serie de servicios a un mercado determinado, creándose las bases institucionales para su utilización como un medio de intervención en la economía al servicio del gobierno. Con ello se cierra un periodo histórico que imponía ciertos límites técnicos e institucionales a la creación de liquidez y comienza otro sistema donde la política de emisión del banco central es utilizada libremente por el gobierno como medio para el desarrollo de la que es considerada como la «mejor política» en cada caso.

Ahora bien, la experiencia monetaria del siglo xx nos revela que las «cadenas doradas» no han sido sustituidas por lo que es «sensato». Es más, la ruptura del régimen de convertibilidad de las emisiones en un patrón metálico abrió una nueva era, caracterizada ahora por la necesidad de interpretación y concreción por parte de las autoridades políticas de lo que se considera como la «mejor política» en cada caso; lo que, en ausencia de un compromiso con un criterio financiero determinado, abrió la posibilidad de tomar medidas discrecionales, ad hoc, que respondieran a lo considerado como "sensato" por el gobierno correspondiente.

Vistas las consecuencias generadas por este sistema de emisión libre y potencialmente arbitrario, se hicieron necesarias nuevas propuestas de regulación de las emisiones del banco central que restringieran la capacidad de actuación de los gestores monetarios, si bien ahora «cadenas no doradas», por la inexis- 
tencia del requisito de convertibilidad de las emisiones en un patrón metálico.

A la hora de entender el diseño de estas nuevas reglas monetarias $^{2}$, resulta de especial importancia el cambio de mentalidad general que provocó la aplicación práctica de los objetivos sintetizados por Keynes, en relación con la posición del banco central dentro de una economía de mercado. En este sentido, independientemente de la idoneidad de los nuevos objetivos planteados por el poder político al banco central, así como de las decisiones en las que se concreta la «mejor política» monetaria en cada momento histórico, esta nueva concepción de la función del banco central en la economía, generalizada a partir de los años treinta, ha generado unas consecuencias aún presentes en las instituciones políticas y académicas de nuestros días. En concreto, este cambio de mentalidad se manifiesta fundamentalmente en el abandono de la consideración del banco central como una institución de naturaleza bancaria y, por tanto, con objetivos relacionados con la intermediación financiera. Así, frecuentemente se nos presenta como una institución que regula las condiciones de crédito de la economía «desde fuera» del mercado, a partir de un criterio dado políticamente.

Para ello, se le ha caracterizado mayoritariamente como una institución arbitral, con poder coercitivo para regular el modo y grado en que las instituciones de crédito emiten pasivos financieros con capacidad para liquidar operaciones en su área monetaria de referencia (véase Goodhart, 1988). De acuerdo con esta manera de entender la posición del banco central, parece como si éste, a pesar de proveer una serie de servicios propios de la

${ }^{2}$ Nos referimos a una regla monetaria cuando la estrategia de un banco central se establece públicamente, de manera clara y por anticipado, a través del anuncio de un compromiso con unas pautas que guiarán sus decisiones en un plazo de tiempo determinado. Por tanto, la discrecionalidad no la identificamos con la toma de decisiones sin un patrón de comportamiento, sino con la toma de decisiones no restringidas por un compromiso comunicado por anticipado. 
intermediación financiera, observara el desarrollo del proceso de creación de liquidez de una manera alejada y desinteresada, con lo que sus decisiones se explicarían dentro de un esquema teórico que lo contempla como una institución pública, ajena al negocio bancario y sujeta a la consecución de objetivos relacionados con lo considerado como representativo del «bien público»o «interés general».

Ahora bien, la consideración del «bien público» como criterio general que ha de regir las competencias del banco central no se ha plasmado a lo largo de los años de forma única. Es más, durante una parte importante del siglo $x x$, el «bien público» en asuntos monetarios se ha identificado con el bien del sector público y, más concretamente, con el bien de las finanzas públicas, plasmado de hecho en la cobertura monetaria garantizada de las necesidades de financiación del Estado. Este modo de entender los principios que han de gobernar las competencias del banco central no sólo se realiza desde una perspectiva que lo aleja del negocio bancario, sino que, además, puede incluso llevarlo a tomar medidas contrarias a los intereses de la institución emisora del pasivo financiero de referencia de la economía. Inspirados en modelos de corte keynesiano, esta forma de gobernar las emisiones del banco central condujo, fundamentalmente a partir del final de los regímenes de convertibilidad de las emisiones, a la subordinación efectiva, tanto orgánica como funcional, de las decisiones del banco central a la consecución de los objetivos de la política económica del gobierno correspondiente; una subordinación que, a la postre, resultó contraproducente.

De esta manera, durante alrededor de medio siglo (19201970) se vio como «natural» la instrumentación de las decisiones monetarias de acuerdo con criterios de naturaleza política, que respondieran a lo que el partido gobernante en cada momento entendía como la expresión práctica del llamado «interés general». Esta forma de fijar los objetivos del banco cen- 
tral se consideró como un paso más hacia el progreso de la sociedad, posibilitado por la aplicación creciente de la Economía, concebida como ciencia social que permitiría guiar racionalmente las decisiones asignativas de los individuos y, asimismo, otorgar al gobernante una función que le permitiría tomar decisiones concernientes al bienestar de toda la sociedad. Ahora bien, esta interpretación y uso del conjunto de conocimientos aportado por la Economía responde a un cierto ejercicio de ingeniería social (Popper, 1945) que, dando licencia para distintos grados de intervención en el mercado monetario, llevó a regular crecientemente las competencias del banco central de acuerdo con una presunción que establecía, ya sea implícita o explícitamente, su capacidad técnica para tomar en cada momento la medida deseada y conseguir los fines propuestos. Con ello, la consideración de las decisiones del banco central como decisiones libres y plenamente capaces de alcanzar los objetivos señalados, insertó el estudio de la idoneidad de su regla de emisión en el marco de la elección de los modelos macroeconómicos que permitieran relacionar óptimamente las herramientas de intervención del sector público con los objetivos generales de la política económica del gobierno de turno.

De este modo, durante una gran parte del siglo xx se entendió la evolución de las funciones del banco central, desde una institución originalmente autónoma y de naturaleza financiera, hacia las de un departamento administrativo más al servicio del gobierno correspondiente; y ello se presentó como el resultado lógico y «natural» de un progreso paralelo en el conocimiento y aplicación de los medios que tiene el gobierno a su disposición para alcanzar los objetivos políticos deseados en cada caso concreto. En este contexto político e intelectual, la aparición en 1959 del trabajo de M. Friedman, A Program for Monetary Stability, fue, en cierta medida, «revolucionaria».

La identificación de los problemas de información a los que se enfrentaba el gestor de la política monetaria permitió a M. 
Friedman hacer hincapié en las limitaciones con las que, irremediablemente, se enfrentaría todo aquel que quisiera regular las emisiones del banco central como medio para alcanzar determinados objetivos de naturaleza política. Con ello, la simple consideración de los posibles resultados desestabilizadores de una política monetaria desarrollada en un medio parcialmente incierto, así como con un conjunto de información reducido y obtenido con cierto retraso, aconsejaba la reducción del conjunto de objetivos al alcance del banco central, así como la limitación de su propia capacidad de intervención en el mercado monetario. De este modo, M. Friedman, desde el propio paradigma neoclásico dominante, incitó a una mayor modestia sobre el alcance del conocimiento disponible, que, cuanto menos, redujo el ámbito de lo deseable, al margen de lo factible, de los objetivos reflejados en los programas de intervención emanados del ingeniero social correspondiente.

Por tanto, en este nuevo contexto teórico dominante acerca del estado real del conocimiento del banco central de las consecuencias finales de sus decisiones, ya no resultaba realista plantear su estrategia de actuación como si pudiera alcanzar los fines de política general propuestos por la autoridad política. Es más, de acuerdo con las consecuencias derivadas de este reconocimiento de las limitaciones de la autoridad monetaria, sería más razonable limitar los objetivos de la política monetaria a un conjunto de objetivos a su alcance. Tanto estos nuevos objetivos de ámbito más limitado como los procedimientos necesarios para su consecución se regularon a través de reformas institucionales que devolvieron al banco central parte de sus características originales. Ello se ha traducido desde entonces en la propuesta mayoritaria de nuevas "cadenas", ahora enteramente fiduciarias, impuestas a la elección del banco central de sus objetivos y procedimientos de actuación. De hecho, la propuesta teórica y el establecimiento efectivo de una regla de emisión para el banco central, mediante la fijación de 
un objetivo estrictamente monetario a su alcance, no supuso más que una vuelta parcial a la disciplina tradicional de sus emisiones, que continúa la línea argumental de los «viejos» patrones metálicos.

Sin embargo, siguiendo las recomendaciones emanadas de la obra de M. Friedman, este retorno al establecimiento de procesos de decisión reglados se enmarca dentro de una perspectiva metodológica y un cuerpo teórico insuficientes para los propósitos de este trabajo.

Por un lado, la vuelta a procesos de decisión reglados ha servido como medio para devolver a esta institución algunas de sus características tradicionales. Desde la segunda mitad de la década de los setenta, ya sea formalmente o a través de la práctica cotidiana, ha venido aumentando el grado de autonomía e independencia operativas del banco central en los principales países desarrollados, desvinculando así, cada vez más, sus decisiones monetarias de las necesidades de financiación del sector público.

Pero, por otro lado, este cambio de perspectiva sigue muy lejos de traer consigo una transformación completa de la naturaleza de la institución financiera de referencia de la economía. De hecho, se sigue analizando el comportamiento del banco central a través de modelos macroeconómicos que explican «desde fuera» su política de concesión de créditos a las entidades financieras, como si, «natural» y definitivamente, su papel fuera tan sólo el de un árbitro externo, desinteresado, regulador del proceso de creación de liquidez, a partir un criterio que surge de una determinada interpretación del «bien público».

Estas nuevas regulaciones de los procedimientos de decisión del banco central parten de unos supuestos políticos muy distintos de los de la época de vigencia de los patrones de convertibilidad, coincidiendo con los supuestos de la época de discrecionalidad en un punto fundamental: se sigue viendo al banco central como una institución al servicio de lo que el 
gobierno interpreta como el mejor funcionamiento agregado de la economía. Así hay que entender el consenso general sobre los objetivos que deben regir la política monetaria del banco central, entre los que prima actualmente el objetivo de estabilidad de precios; consenso que, expresado mayoritariamente en los propios estatutos reguladores de estas instituciones, recoge lo que se entiende por la «mejor política» monetaria en este momento histórico.

Cierto es que, con el retorno a los regímenes que restringen la capacidad de decisión del gestor de la política monetaria, se ha producido un cambio significativo de lo que se ha venido entendiendo por el concepto general de «bien público» como criterio final que ha de regir las decisiones del banco central; en concreto, se ha pasado de la sujeción de las decisiones monetarias a la financiación incondicional y privilegiada de la Hacienda Pública, a la preservación de la estabilidad de precios a largo plazo. Asimismo, se han diseñado y puesto en práctica procedimientos de decisión que se aproximan a una pauta de actuación crecientemente reglada, lo que supone una vuelta a los esquemas tradicionales que limitaban las emisiones de los bancos centrales, si bien ahora en contextos puramente fiduciarios. Ahora bien, tanto el objetivo de la estabilidad de precios como los procedimientos desarrollados para su consecución aparecen como elementos aportados desde fuera del ámbito operativo del banco central, ya sea a partir de un mandato emanado de las instituciones políticas, ya sea generado por la influencia del consenso académico vigente en cada época ${ }^{3}$.

Es precisamente la generación externa de estas propuestas de actuación del banco central lo que las convierte necesa-

3 T. Mayer (1998), a la hora de explicar la evolución de la política monetaria reciente de la Reserva Federal, otorga cada vez más importancia al peso de los consensos académicos y doctrinales aceptados en cada momento histórico, representados crecientemente a través de destacados profesores universitarios en los órganos de gobierno de la autoridad monetaria. 
riamente en propuestas inestables, dependientes tanto del conjunto de valores socio-políticos como de las creencias científicas vigentes en cada periodo histórico. Sería, pues, un error representar la historia de la banca central como una historia de progreso continuo y armónico, fruto de la selección natural de las instituciones generadoras del mayor bienestar de los ciudadanos. Por el contrario, en el ámbito que nos ocupa, la interpretación externa del concepto de «bien público» como inspirador de la actuación del banco central, lejos de ser un avance necesario, más bien parece ser el resultado de un proceso de intervención pública que abre la posibilidad de prácticas regresivas, sometidas a continuos cambios y correcciones de rumbo. Con ello, la aplicación histórica del concepto de «bien público» en asuntos monetarios puede describirse más fielmente como un proceso circular, de «idas y venidas», que implica la presencia de bruscos saltos hacia distintas concepciones de lo que es mejor para la sociedad. De este modo, el objetivo, hoy en día generalizado, de la consecución de la estabilidad de precios refleja uno de los consensos posibles sobre el mejor objetivo que puede plantearse actualmente el banco central; consenso que depende, en última instancia, del conjunto de valores y creencias políticas y académicas mantenidas en la sociedad en un determinado momento histórico.

La vigencia actual de esta forma de entender la política monetaria se ha plasmado en el empleo de una perspectiva de análisis agregada, basada en la Ecuación Cuantitativa del Dinero, que prescribe la consecución de un objetivo como la estabilidad de precios como medio para alcanzar un equilibrio macroeconómico en los mercados real y monetario. A diferencia de este planteamiento metodológico, en este trabajo presentamos un análisis microeconómico de las decisiones del banco central que precisamente pone en cuestión la vigencia de la estabilidad de precios como el mejor objetivo posible para el correcto desarrollo del mercado como mecanismo de asignación de recursos. 


\section{OBJETIVO DEL BANCO CENTRAL COMO BANCO DE REFERENCIA DE UN CLUB DE ENTIDADES FINANCIERAS ASOCIADAS}

\section{Banco de referencia de un $c l u b$ de bancos asociados: enfoque microeconómico}

Las decisiones del banco central, así como también los efectos de sus medidas monetarias, se pueden caracterizar y analizar, respectivamente, desde una perspectiva metodológica que reconsidere al banco central como una institución de naturaleza fundamentalmente financiera, que presta una serie de servicios a un conjunto de entidades de crédito asociadas; servicios entre los que destacamos la emisión del patrón monetario de referencia del conjunto de las emisiones del sistema financiero.

Su caracterización como banco de referencia de un club de entidades financieras asociadas (Goodhart, 1988) nos permite estudiar sus criterios de emisión desde un enfoque microeconómico que analice desde dentro sus decisiones como decisiones generadas y explicadas por su posición como banco proveedor de servicios financieros al resto de entidades financieras. Siguiendo esta caracterización, el banco central proveería una serie de servicios financieros, emanados de su posición como emisor del patrón de referencia del conjunto de las emisiones de las entidades financieras: el préstamo regular y extraordinario, la compensación centralizada de saldos y el depósito de las reservas de liquidez de las entidades financieras.

Cada una de las entidades financieras pertenecientes al citado club emitirá, en el ejercicio de su actividad empresarial ordinaria, distintos títulos financieros, de características muy heterogéneas entre sí, si bien compartiendo todas ellas su denominación en el patrón monetario emitido por el banco central 
(esto es, el llamado dinero externo ${ }^{4}$ de la economía). Dependiendo del grado de liquidez de estos títulos financieros, serán medios de pago útiles para la realización de operaciones cotidianas de intercambio y ahorro, por lo que se denominan genéricamente como dinero interno ${ }^{5}$.

Por tanto, como anticiparon los principales autores de la Escuela Austriaca de Economía, en un sistema de monopolio de emisión de moneda de curso legal, este monopolio no se extiende al resto de pasivos que pueden ser emitidos por el resto de entidades financieras (Hayek, 1932). De este modo, si bien el banco central es el único autorizado para emitir un tipo de pasivos como son los billetes de pago a la vista, el resto de entidades financieras emiten pasivos con distinto grado de liquidez y rentabilidad, que compiten de hecho, tanto entre sí como con el propio banco central, en la satisfacción de las necesidades de intercambio y ahorro de los agentes ${ }^{6}$.

${ }^{4}$ Utilizaremos la definición convencional de dinero externo ("outside money») aportada por Friedman y Schwartz (1963), que consiste en el patrón de liquidez última del sistema, que sirve de referencia para el resto de emisiones del sistema monetario (esto es, los billetes en circulación y las reservas bancarias que constituyen la base monetaria). Por tanto, en adelante utilizaremos como términos sinónimos el patrón monetario de la economía, la fuente última de liquidez del sistema monetario o el dinero externo. Este patrón se ha identificado históricamente con las reservas de oro u otro metal precioso, por ser los bienes que, a través de los años y la experiencia acumulada, se han ido seleccionando por su mayor grado de liquidez en los intercambios cotidianos. Sin embargo, en la actualidad el dinero externo constituye un patrón fiduciario puro, por la ausencia de convertibilidad del mismo en ningún activo real.

5 Se entenderá por dinero interno («inside money») el conjunto de medios o efectos de pago de circulación en la economía denominados en su correspondiente patrón monetario. En este sentido, los pasivos altamente líquidos emitidos por las entidades financieras - esto es, el llamado dinero bancario— se considerarán como un tipo de dinero interno, emitido por parte de las entidades bancarias.

6 Por ello, hay una competencia real en la emisión del resto de pasivos que, con distinto grado de liquidez, se utilizan como sustitutivos del dinero del banco central. Para un estudio de las características de los medios utilizados para realizar intercambios, puede consultarse el concepto de grado de dinerabilidad (o liquidez) de los bienes en Hayek (1978), basado en la teoría del origen del dinero aportada por Menger (1871). 
El banco central, como proveedor de este patrón monetario que sirve de referencia de valor al resto de las emisiones de medios de pago, está proveyendo un servicio fundamental para la garantía y credibilidad de dichas emisiones. En concreto, en tanto en cuanto las emisiones de dinero externo consigan mantener la confianza general en el mantenimiento de su poder adquisitivo, los agentes aceptarán con mayor facilidad la realización de sus operaciones de intercambio y de depósito de parte de su riqueza a través de los billetes emitidos por el banco central y del resto de pasivos financieros emitidos por las entidades financieras.

Por ello, redunda en el propio beneficio del banco central, en cuanto proveedor del patrón de liquidez último de la economía, el establecimiento de una regla de emisión que consiga tanto la mayor utilización posible de su propia moneda como la del resto de medios denominados por ley en dicha moneda. Al tratarse de beneficios asociados a la emisión de medios de pago, este beneficio se conoce bajo la denominación de señoreaje de emisión $n^{7}$. Si bien, tradicionalmente, se ha supuesto que este señoreaje sólo era percibido por el banco central (véase White, 1999), la posibilidad de crear medios de pago a partir de los depósitos recibidos por las entidades financieras, en sistemas

7 Puede consultarse la definición convencional dada por S. Black (1992): «The excess of the face value over the cost of production of currency is also called seignioraje, because it accrued to the seigneur or ruler who issued the currency in early times».

$S_{t}=\left(\frac{\mathrm{M}_{t}^{s}-\mathrm{M}_{t-1}^{s}}{\mathrm{M}_{t-1}^{S}}\right)\left(\frac{\mathrm{M}^{D}}{\mathrm{P}}\right)_{t}$

Esta expresión del señoreaje puede interpretarse como el «impuesto» establecido por el monopolista de emisión de dinero externo (White, 1999), dado que el aumento de la oferta monetaria representaría el tipo impositivo correspondiente y la demanda de saldos reales su base de aplicación. Por ello, el banco central puede aumentar su señoreaje con la aplicación de una política de emisión compatible con la potenciación de la demanda de dinero a largo plazo, esto es, con la ampliación de la base sujeta al impuesto. 
de reserva fraccionaria ${ }^{8}$, crea las condiciones institucionales necesarias para permitir al resto de entidades financieras la emisión de medios de pago por un valor facial superior al coste incurrido en su emisión, por lo que el señoreaje se extiende, de hecho, al conjunto de entidades emisoras de medios de pago.

Ahora bien, la obtención del señoreaje en la emisión de dinero interno por parte de las entidades financieras está actualmente restringida legal y técnicamente. El señoreaje de emisión de dinero interno está necesariamente limitado por la exigencia de convertibilidad de los depósitos bancarios en billetes de la moneda de curso legal. Por ello, la política de creación de dinero interno en forma de depósitos está legalmente restringida por la necesidad de mantener los recursos suficientes para asegurar su convertibilidad en la moneda de curso legal, a través de la devolución en el momento requerido de la cantidad equivalente del patrón monetario9.

En todo caso, al margen de la cláusula de curso legal de la moneda emitida por el banco central, en todo sistema de reserva centralizada, la política de emisión de pasivos de las entidades de crédito está influida en última instancia por la necesidad de mantener cierto volumen de reservas de liquidez en forma de la moneda externa, en previsión de solicitudes de liquidez de sus clientes. Con ello se establece un sistema de crea-

8 Tal y como detalla Huerta de Soto (1998), este sistema de reserva fraccionaria es lo que permite la emisión de nuevos medios de pago a partir de los depósitos recibidos. Por ello, entenderemos el señoreaje en un sentido más amplio, incluyendo no sólo el que nace de la diferencia entre el valor facial de un billete y su coste de fabricación, sino también el generado por la posibilidad de crear ex novo medios de pago, con su respectivo valor facial, a partir de la obligación de mantener como reserva únicamente una proporción de los depósitos recibidos.

9 Por tanto, es un sistema que permite a los bancos actuar con un coeficiente de caja menor al 100\% de los depósitos, si bien habrán de seguir una política de inversiones que les permita atender a las demandas periódicas de dinero externo. Tal y como señala White (1999), el requisito de convertibilidad obligatoria de las emisiones de dinero interno en el patrón monetario correspondiente, si bien limita su volumen, no implica necesariamente el mantenimiento de un respaldo del 100\% de ellas en todo momento. 
ción de liquidez descentralizado, donde se reparten las ganancias de emisión de moneda entre el banco central y los creadores de depósitos bancarios miembros del $c l u b$, si bien de reserva única y centralizada, que resulta altamente dependiente de las decisiones del emisor del patrón último de liquidez del mercado. De este modo, tenemos un sistema de creación múltiple de liquidez que limita la capacidad de emisión del dinero interno, controlado en última instancia por el emisor del patrón monetario.

Asimismo, a diferencia de los sistemas monetarios metálicos tradicionales, es un sistema fiduciario puro, dado que el patrón de liquidez última de la economía está constituido por las emisiones no convertibles del banco central. Por tanto, en ausencia de alguna restricción legal al respecto, este sistema monetario, a diferencia del proceso de creación del dinero interno, permite, de hecho, el desarrollo de una política de emisión del patrón monetario libre o no restringida. Es precisamente en este tipo de sistemas monetarios donde adquiere especial relevancia la adopción de una regla monetaria que comprometa ex ante la política de emisión del monopolista de dinero externo; regla que ha de considerar un entorno de actuación caracterizado por los siguientes elementos:

- La existencia de una competencia de hecho en la emisión de dinero interno, caracterizada por la emisión de pasivos financieros con distinto grado de dinerabilidad (Hayek, 1978), que genera un reparto del señoreaje de emisión entre el banco central y el resto de entidades financieras.

- El mercado financiero actual (King, 1999; Jordan y Stevens, 1996) ${ }^{10}$ muestra un aumento de la competencia existente en

10 Resulta especialmente significativo que sean precisamente dos miembros cualificados de los órganos de gobierno de dos bancos centrales de referencia internacional como el Banco de Inglaterra y la Reserva Federal de EE.UU., M. King y J. Jordan respectivamente, quienes apunten una tendencia del mercado hacia una 
la provisión de medios de pago entre las instituciones de crédito, tanto por su creciente capacidad de acceso a los servicios financieros de otros bancos centrales y de creación de pasivos en diversas monedas, como por la aparición de nuevos emisores de pasivos líquidos, ajenos al club de bancos asociados al banco central, con capacidad técnica para competir en la provisión de los medios disponibles para realizar intercambios cotidianos.

- El uso del patrón monetario, así como del resto de medios de pago, depende de su grado de satisfacción de las necesidades de los demandantes de dinero.

Ante este escenario de creciente competencia en el mercado monetario, el banco central se enfrenta, fundamentalmente, a dos opciones alternativas: una perteneciente al pasado, la de reforzar su monopolio de emisión, intentando controlar legal y técnicamente su mercado; otra, más adecuada a las nuevas características de los mercados financieros, la de mejorar sus servicios financieros característicos, como medio para atraer a los nuevos oferentes de pasivos e impedir la salida de los ya existentes. En este trabajo nos ocupamos precisamente de enmarcar las decisiones del banco central en el contexto de esta estructura dinámica y competitiva del mercado y, asimismo, de proponer unos objetivos de actuación compatibles con sus intereses particulares como la institución financiera emisora del patrón monetario de la economía.

De esta manera, planteamos un esquema de análisis alternativo de las decisiones del banco central que tome en cuenta sus intereses particulares, así como la repercusión del entorno

potencial reducción de la capacidad real de intervención y control de los bancos centrales en el ámbito de las funciones emanadas del curso legal exclusivo de su moneda. A partir del reconocimiento de esta tendencia del mercado, en Castañeda y Schwartz (2001) puede encontrarse una propuesta de reforma de las competencias del BCE en consonancia con este entorno de creciente competencia monetaria. 
monetario que le rodea, como fuentes endógenas que nos permitan explicar la elección de sus objetivos. Como consecuencia de este análisis de mercado, podemos sustituir la discusión teórica convencional relativa a los fines que deben regir las emisiones del banco central, basada en la elección «externa» de un objetivo macroeconómico que represente el consenso político y académico de cada momento «de lo que es mejor para la sociedad», por la discusión de los fines de la regla de emisión, atendiendo a un estudio de los intereses particulares de la institución en torno al mejor modo en que puede prestar sus servicios financieros. Por ello, la elección del objetivo último de su política monetaria no será tanto el resultado de un proceso de elección libre de aquel que represente las preferencias políticas de cada época correspondiente, sino más bien de aquel que consiga conciliar las preferencias del banco central con las de los usuarios directos e indirectos del sistema monetario.

Con ello, el criterio de emisión del patrón monetario pasa a concebirse como un criterio de mercado, que depende de su capacidad para satisfacer las necesidades de los usuarios del sistema financiero como medio para aumentar sus ganancias de señoreaje de emisión a lo largo del tiempo. En este sentido, el buen funcionamiento del sistema de creación de liquidez pasa a ser un objetivo explicado por la persecución del interés del proveedor del patrón monetario (Bagehot, 1873). Asimismo, en este contexto, el banco central no adopta expresamente un objetivo macroeconómico, si bien estará interesado en un desarrollo estable de la economía, en la medida en que ello redundaría positivamente en sus ganancias por el señoreaje de emisión a lo largo del tiempo, lo que no se conseguirá necesariamente con la consecución de la estabilidad de precios. Por ello, la estabilidad de la economía pasa a ser un objetivo endógeno de un banco central que persigue el aumento de sus ganancias de señoreaje a lo largo del tiempo. 


\section{ESPECIFICACIÓN DE LA REGLA DE EMISIÓN COMPATIBLE CON LOS OBJETIVOS DE MERCADO DEL BANCO CENTRAL}

\section{Análisis de los efectos de tres tipos de criterios de emisión}

a) Criterio de emisión inflacionista: Caso de un aumento de la oferta monetaria en una economía estacionaria ${ }^{11}$

En primer lugar, el desarrollo de un criterio de emisión inflacionista, ya sea por la dificultad de interpretación de sus consecuencias futuras, ya sea por la existencia a corto plazo de ciertas rigideces institucionales que impiden la adaptación de los agentes a una posible previsión inflacionista, puede permitir al banco central conseguir un aumento inicial de la demanda de medios altamente líquidos. Ahora bien, una vez que sean percibidos los efectos inflacionistas del aumento de la oferta nominal de medios de pago y los agentes puedan alterar su planificación previa, incorporando ahora sus nuevas expectativas, la previsión de inflación reducirá la demanda interna real de los medios líquidos. Asimismo, tal previsión inflacionista se traducirá, por el efecto Fisher (Fisher, 1911), en un aumento del tipo de interés nominal y, finalmente, en la depreciación externa de la moneda, bajo el supuesto de cumplimiento de la Paridad del Poder Adquisitivo a largo plazo. Por ello, en tanto en cuanto las entidades financieras revisen la rentabilidad ofrecida de sus pasivos a la inflación prevista, se producirá un cambio del reparto del señoreaje entre el banco central y el resto de emisores, dado el desplazamiento de la demanda entre los usuarios de dinero interno hacia los pasivos que, al menos, mantienen parcialmente el poder de compra de su riqueza.

11 Analizaremos los efectos de una expansión monetaria en una economía sin variaciones de la productividad. Por ello, es una regla consistente en la promoción directa de la actividad, teniendo como objetivo un crecimiento de la renta mayor que su tasa de crecimiento no inflacionista a largo plazo. 
Por tanto, considerando el plazo de tiempo suficiente para permitir el ajuste de las decisiones de los agentes a los cambios de la política monetaria ${ }^{12}$, una sobreexpansión de la oferta del patrón monetario tendrá, finalmente, como consecuencia, una reducción de su demanda, dada su depreciación tanto en el interior (por su rentabilidad negativa asociada al aumento previsto de los precios), como en el exterior. Con ello, a partir de la definición de señoreaje planteada, se reduciría presumiblemente la demanda del patrón monetario emitido por el banco central y, con ello, sus beneficios de emisión asociados. Por tanto, desde una perspectiva individual o de negocio bancario, esta política de emisión no será desarrollada por un banco central que persiga aumentar sus ganancias de señoreaje a lo largo del tiempo.

En segundo lugar, desde una perspectiva agregada característica del análisis de la economía neoclásica convencional ${ }^{13}$, el desarrollo sistemático de esta regla monetaria, que contiene un objetivo, implícito o explícito, de inflación positiva (12), no tendrá efectos persistentes sobre la evolución de la actividad o el empleo (Kydland y Prescott, 1977), sino tan sólo efectos agregados sobre variables nominales. Una vez que los agentes conocen cuáles son los objetivos inflacionistas del banco central y pueden prever sus resultados, ajustarán sus decisiones actuales de modo que puedan evitar las consecuencias negativas que tal política de emisión pudiera provocar en el futu-

12 Éste es un plazo que depende no sólo de las características institucionales de los mercados de bienes y factores de la economía considerada, sino también, de manera fundamental, de la información transmitida por el banco central acerca del modo en que toma las decisiones monetarias.

13 Este análisis de las consecuencias macroeconómicas de esta política monetaria inflacionista no considera, por los supuestos metodológicos en que se inscribe, los efectos microeconómicos que generan las sobreemisiones del banco central sobre el sistema de precios y la estructura productiva de la economía, aspectos que sí tendremos en cuenta en el siguiente apartado a la hora de valorar los efectos de una política de estabilización de precios. 
ro sobre el poder adquisitivo de su renta. El resultado será una situación de equilibrio, denominado discrecional, caracterizada por mayores niveles de precios y un crecimiento de la actividad alrededor de su tasa natural o de equilibrio a largo plazo. De hecho, esta política de emisión genera un desequilibrio en el mercado monetario (13), consistente en un exceso de oferta de liquidez; desequilibrio que cesará siempre que los precios puedan ajustarse a tal exceso de oferta. Una vez restaurado el equilibrio monetario (14), se observará que la política desarrollada no habrá tenido efectos reales permanentes, sino tan sólo aumento generalizado y proporcional de los precios de la economía y una mayor inestabilidad de la actividad real a lo largo del ciclo, hasta alcanzar su tasa de variación natural a largo plazo.

$$
\dot{M}_{t}^{S}>\left(\dot{T}_{r}^{e}-\dot{V}^{e}\right)_{t} \Leftrightarrow \Pi_{t}^{*}>0
$$

$$
\begin{aligned}
& \left(\frac{\dot{M}_{t}^{S}}{P_{t}}\right)>\left(\frac{\dot{M}_{t}^{D}}{P_{t}}\right) \\
& \left(\frac{\dot{M}_{t}^{S}}{P_{t+1}^{E}}\right)=\left(\frac{\dot{M}_{t}^{D}}{P_{t}}\right) ; P_{t+1}^{E}>P_{t}
\end{aligned}
$$

Por ello, desde una perspectiva que valore las decisiones del banco central en función de su propio beneficio como banco emisor, beneficio que incluye los efectos macroeconómicos de sus decisiones, una política monetaria consistente en la emisión inflacionista de medios líquidos resultaría poco beneficiosa para el banco central. 
b) Criterio de estabilización de la inflación: caso de un aumento de la oferta monetaria suficiente para financiar una economía en crecimiento

Desde una perspectiva particular del banco central, que lo considere como un banco oferente de una serie de bienes o servicios al mercado, un aumento de la productividad de la economía traerá presumiblemente consigo un aumento paralelo de la demanda interna de medios de pago por dos motivos, lo que aumentará sus ganancias de señoreaje: en primer lugar, por el aumento del número de bienes y servicios que son producidos e intercambiados en la economía (T); en segundo lugar, en ausencia de una medida monetaria expansiva que lo acompañe, el aumento de la oferta disponible de bienes y servicios podrá generar una expectativa de bajada de precios de los bienes y servicios finales, lo que aumentará la demanda relativa de los medios de pago en relación con el resto de pasivos financieros, dada su mayor rentabilidad esperada y, con ello, el tipo de interés. Por tanto, ante una expectativa deflacionista, resultante de un aumento del número de bienes y servicios disponibles, los medios líquidos existentes aumentarán su poder adquisitivo esperado.

Ahora bien, en este contexto de crecimiento de la productividad, la respuesta del banco central consistente en la expansión de la oferta monetaria en una tasa igual al incremento de la capacidad productiva ${ }^{14}$, se traducirá, tras un cierto periodo de tiempo, en un aumento de los precios tal que compensará el posible efecto deflacionista inicial derivado del aumento

14 Esta intervención se justifica (Yeager, 1986) por la necesidad de aumentar la oferta de dinero ante el aumento producido en la demanda de dinero; ahora bien, tal y como señalamos en el siguiente apartado, esta política de persecución del equilibrio en el mercado monetario a través de aumentos de la oferta monetaria puede reemplazarse por otra política que permita la adaptación de los precios de venta de los productores a las variaciones de la productividad registrada en los procesos productivos. 
esperado del volumen de bienes y servicios disponibles. Con ello se eliminaría uno de los factores causantes del aumento de la demanda de dinero del banco central, dada su potencial ganancia de poder adquisitivo y, como consecuencia de ello, de los beneficios por señoreaje asociados a tal aumento ${ }^{15}$.

Por tanto, en principio, es una política de emisión que, no siendo el resultado lógico de un proceso de ajuste de las decisiones del oferente del patrón monetario a un cambio de la demanda de mercado, no responde estrictamente a la persecución de sus objetivos particulares como oferente de servicios en un mercado determinado, sino a otras consideraciones agregadas que pasamos a comentar a continuación.

Desde una perspectiva macroeconómica neoclásica, ésta es una política de emisión compatible con la regla de crecimiento monetario fijo propuesta por Friedman (1959), así como con todas aquellas formulaciones posteriores que vinculan total o parcialmente la oferta de medios de pago a la evolución del crecimiento potencial de la producción de bienes y servicios finales [la regla de Taylor (1993) original y sus reformulaciones posteriores]. Ahora bien, a partir de la utilización de este criterio general de emisión, dadas las importantes diferencias existentes entre las mismas, expondremos los efectos de una política monetaria estabilizadora de los precios a través de dos funciones de reacción ${ }^{16}$ : por un lado, la regla de crecimiento monetario fijo de Friedman (1959) (regla fija, en términos de un agregado

15 Asimismo, esta política monetaria frena otro de los ajustes que tienen lugar en el mercado derivado del aumento de la productividad; a saber, en ausencia de un aumento paralelo de la oferta monetaria, el aumento de la productividad generaría una expectativa de menores precios en el futuro, lo que tenderá a apreciar la moneda. Por ello, en ausencia de la intervención del banco central, aumentaría tanto la demanda interna como la externa de los pasivos denominados en la moneda nacional.

16 De acuerdo con la metodología de optimización de una función objetiva sujeta a una serie de restricciones, Svensson (1998) define matemáticamente la función de reacción como «a single-valued mapping from the predetermined variables to the instruments» (p. 4). 
monetario reducido), y la regla de Taylor (1993) (regla activa, en términos del tipo de interés nominal a corto plazo).

(i) Análisis de los efectos de la regla de crecimiento monetario fijo

De acuerdo con la propuesta teórica de Friedman (1959), el banco central sólo ha de aumentar la oferta monetaria si, una vez descontada la variación estimada de la velocidad de circulación del dinero, estima un crecimiento real de la economía a largo plazo, de modo que la oferta de dinero responda únicamente ante aumentos reales y sostenidos de la demanda de dinero (15). Detrás de esta propuesta se encuentra la presunción teórica consistente en que toda variación de precios es un indicador de un desequilibrio monetario y, con ello, una causa de posibles desequilibrios en el mercado de bienes y servicios (16.a, 16.b) (Johnson, 1968; Yeager, 1986).

Si se produce un exceso de oferta de dinero, ello se traducirá en un aumento de la demanda de bienes y servicios finales (desequilibrio real), que tendrá como consecuencia un aumento de los precios. Por el contrario, si se produce un exceso de demanda de dinero, la escasez de medios de pago se traducirá en un exceso de oferta de bienes y servicios finales (desequilibrio real), que se corregirá a través de una bajada de los precios. En ambos casos, de acuerdo con este análisis del equilibrio de mercado, es el movimiento de ajuste de los precios lo que permite corregir la situación de desequilibrio causada en los mercados de bienes y servicios.

Ahora bien, estos movimientos correctores no son ni inmediatos ni, en muchos casos, posibles. Por tanto, si ante un aumento de la productividad aumenta la demanda de medios líquidos y, simultáneamente, la situación de exceso de oferta de bienes y servicios no se corrige a través de una bajada de los precios, se tendrá como consecuencia una bajada de las ventas de 
los productores y una caída de los niveles de renta de la economía. De este modo se justifica, a través del supuesto teórico que mantiene la existencia de cierta rigidez a la baja de precios y salarios, el desarrollo de una política monetaria que provoque las variaciones requeridas en cada caso en los precios, como medio para evitar ajustes no deseados de la producción en los mercados de bienes y servicios (Yeager, 1986; Selgin, 1997).

Con ello, la oferta monetaria habrá de variar en el mismo sentido que la productividad de la economía, asegurando así en todo momento la consecución de un equilibrio monetario que permita, paralelamente, alcanzar una situación de equilibrio en los mercados de bienes y servicios alrededor de la tasa de crecimiento real de equilibrio a largo plazo de la economía $\left(\dot{T}_{r}\right)(15)$.

$\dot{M}_{t}^{S}=\left(\Pi^{*}+\dot{T}_{r}^{e}-\dot{V}^{e}\right)_{t}=\left(\dot{T}_{r}^{e}-\dot{V}^{e}\right)_{t} \Leftrightarrow \Pi_{t}^{*}=0$

$\left(\frac{\dot{M}_{t}^{S}}{P_{t}}\right)=\left(\frac{\dot{M}_{t}^{D}}{P_{t}}\right) \Leftrightarrow\left(D_{t}^{B}\right)=\left(S_{t}^{B}\right) \Leftrightarrow P$ estables $\Leftrightarrow \Pi_{t}^{*}=0$

Si los precios son flexibles:

$$
\left\{\begin{array}{l}
\left(\frac{\dot{M}_{t}^{S}}{P_{t}}\right)>\left(\frac{\dot{M}_{t}^{D}}{P_{t}}\right) \Leftrightarrow\left(D_{t}^{B}\right)>\left(S_{t}^{B}\right) \Rightarrow \Delta P \\
\left(\frac{\dot{M}_{t}^{S}}{P_{t}}\right)<\left(\frac{\dot{M}_{t}^{D}}{P_{t}}\right) \Leftrightarrow\left(D_{t}^{B}\right)<\left(S_{t}^{B}\right) \Rightarrow \nabla P
\end{array}\right.
$$

Siendo:

$-D_{t}^{B}$ la demanda de bienes y servicios

$-S_{t}^{B}$ la oferta de bienes y servicios 
Con ello, tal y como señala Friedman (1956, 1959), se pretendería garantizar el equilibrio en el mercado monetario (16) como medio para no provocar efectos reales en una economía en la que se supone, al menos a corto plazo, la existencia de ciertas rigideces institucionales que impedirían el ajuste automático de los precios y salarios a los cambios de demanda; lo que se denomina como el desarrollo de una política monetaria neutral, dado que no tiene efectos persistentes sobre la tasa de crecimiento real de la economía a largo plazo ${ }^{17}$. De este modo, si el ajuste no puede lograrse a partir de un proceso de revisión natural de las decisiones individuales de los agentes a las circunstancias cambiantes del proceso productivo, el banco central ha de provocar el necesario ajuste a través de la modificación del volumen de medios de pago en circulación. Por tanto, en opinión de los defensores de este criterio de emisión basado en la obra de Friedman (1959), ante un aumento de la productividad, la «mejor» política monetaria será la de impedir el desequilibrio monetario generado y, por ello, debe reaccionarse aumentando proporcionalmente la cantidad de liquidez en circulación (17), con lo que se garantizará una evolución estable de los precios a lo largo del tiempo.

Si $\Delta$ Productividad $\Rightarrow \Delta M_{t+1}^{D}=\Delta M_{t+1}^{S} \Rightarrow$

$$
\Rightarrow\left(\frac{\dot{M}_{t+1}^{S}}{P_{t}}\right)=\left(\frac{\dot{M}_{t+1}^{D}}{P_{t}}\right) \Leftrightarrow P_{t} \text { estables }
$$

17 Puede consultarse la evolución y el significado de este término en Patinkin y Steiger (1989) y Patinkin (1992). Como veremos más adelante, esta política monetaria antiinflacionista no es neutral en sentido estricto, ya que es un concepto inscrito en un análisis del equilibrio agregado que no recoge los cambios que provoca la política monetaria en la estructura productiva de la economía. 
(ii) Análisis de los efectos de la regla de Taylor

Si utilizamos la regla de Taylor (18), los resultados son semejantes. De acuerdo con ella, el banco central deberá abaratar las condiciones de crédito y, por tanto, permitir un aumento de la tasa de creación de liquidez, siempre que aumente la capacidad productiva de la economía. En este contexto, un crecimiento de la productividad genera un output gap ${ }^{18}$ positivo que debe ser «aprovechado» por el gestor de la política monetaria. De hecho, la definición del output gap está basada en la estimación de la diferencia entre el valor de la producción registrada de bienes y servicios respecto a una variable indicativa de su capacidad productiva potencial, consistente en aquella tasa de crecimiento equilibrado a largo plazo de la producción y, por tanto, compatible con una evolución estable de los precios (Taylor, 1998, 1999).

$$
i_{n o m, t}^{T}=i_{r}^{*}+\Pi^{e}+g_{1}\left(\Pi_{t}-\Pi^{*}\right)+g_{2}\left(\dot{\mathrm{Y}}_{r, t}-\mathrm{Y}^{*}\right)
$$

Por tanto, si se produce un aumento de la productividad, se registrará a largo plazo un exceso de oferta de bienes y servi$\operatorname{cios}\left(\dot{\mathrm{Y}}_{r, t}<\mathrm{Y}^{*}\right)$ (escasez de medios líquidos) y, como consecuencia de ello, un descenso de la inflación por debajo de la tasa fijada inicialmente como objetivo. Una vez que sean percibidos estos efectos, esta función de reacción no sólo permite, sino que, además, explicita la función estabilizadora ${ }^{19}$ de la política monetaria alrededor de $« \dot{\mathrm{Y}}_{r} » \mathrm{y} « \Pi^{*} »$, a través de una política de emi-

18 Si bien no vamos a entrar en más detalle, esta regla de emisión es, en sentido estricto, no operativa. Tanto el conjunto de información que supone conocido, como la controversia existente en torno a los métodos de medición del output gap, la convierten en una regla inaplicable en la realidad.

19 Asimismo, si el objetivo de inflación, una vez considerado el sesgo de sobreestimación de la inflación (Boskin et al., 1996), es positivo, la estabilización de la política monetaria no será realmente alrededor de la tasa de producción potencial, sino alrededor de una tasa aún mayor. Por ello, a diferencia de la propuesta por Friedman, la regla de Taylor permite en su formulación teórica una capacidad estabilizadora mayor $\mathrm{y}$, por tanto, la toma de decisiones monetarias estrictamente inflacionistas. 
sión expansiva, consistente en una reducción del tipo de interés de préstamo a las entidades financieras. De este modo se pone de manifiesto una de las características diferenciales de la regla de Taylor, a saber, su elevado grado de activismo, dada la prescripción de intervención del banco central para conseguir el equilibrio monetario tanto a largo plazo como, asimismo, a lo largo del ciclo económico.

A modo de conclusión, la aplicación de este criterio de emisión a través de las funciones de reacción señaladas prescribiría la reducción del tipo de interés de mercado en una situación de bajadas de precios producidas por un aumento de la productividad y, por tanto, de la demanda de dinero y del tipo de interés natural. Con ello, en términos del análisis tradicional del ciclo realizado originalmente por Wicksell (1907) y Mises (1912), se estaría fijando un tipo de interés de mercado por debajo o, incluso, en sentido contrario a la evolución tendencial del tipo de interés natural o de equilibrio de la economía, lo que generaría un exceso de demanda de bienes de inversión que conduciría, finalmente, a una situación insostenible a largo plazo, caracterizada por una senda de crecimiento de la producción real por encima de su tasa de crecimiento de equilibrio y, paralelamente, por un aumento intencionado del nivel de precios. Por ello, se estaría desarrollando una política de emisión realmente no neutral, contraria a una evolución estable de la economía y, con ello, contraria a los intereses del banco emisor.

c) Criterio de estabilización de la renta nominal: caso de una variación de la oferta monetaria en función de la evolución de la renta nominal

Bajo el supuesto de una economía en crecimiento, las mejoras productivas generarán un número creciente de bienes y servicios en la economía. $\mathrm{Si}$, ante esta situación, el banco central establece una política de emisión que no vincule necesaria y úni- 
camente el volumen de pasivos líquidos a la evolución paralela de la productividad, los resultados sobre los beneficios por el señoreaje serían presumiblemente los ya señalados con anterioridad. En primer lugar, se producirá a largo plazo un aumento del volumen de transacciones realizadas en la economía, dado el crecimiento supuesto de la capacidad productiva. En segundo lugar, el aumento de la productividad se traducirá en un aumento de la oferta de bienes y servicios y, por tanto, en una expectativa a medio y largo plazo de reducción de los precios en mercados potencialmente abiertos ${ }^{20}$, lo que generará tanto un aumento del valor de los pasivos denominados en la moneda correspondiente como de la rentabilidad del dinero de curso legal. En tercer lugar, la mayor capacidad de compra de los medios de pago se reflejará en su apreciación externa, por lo que aumentará igualmente su demanda externa.

En este contexto, tanto el banco central como el resto de entidades emisoras de pasivos financieros encontrarán esta situación como beneficiosa de acuerdo con sus intereses particulares. Analizaremos a continuación si una política de emisión orientada a la obtención de un beneficio a largo plazo del emisor del patrón monetario es compatible con el buen desarrollo agregado del conjunto de la economía, entendiendo como tal una regla de emisión que permita una evolución estable de la estructura productiva, que no provoque distorsiones sobre la evolución cíclica de la actividad real en el medio y largo plazo.

De acuerdo con la exposición original de Hayek (1928), una regla de emisión que prescribe la evolución de la liquidez en función de la renta o producción nominal $\left(\mathrm{T}_{\text {nom }}\right)$ de la economía, por su propia definición (19), no tiene un objetivo de estabilización individual ni de la renta o producción real, ni del nivel

20 En siguientes epígrafes mostraremos que podemos mantener el supuesto de deflación tendencial o a largo plazo, si bien considerando la posibilidad de existencia de mercados imperfectos que no permitan trasladar en su totalidad la variación de la oferta productiva en los precios a lo largo del tiempo. 
de precios. Es más, es una regla que precisamente requiere movimientos de ajuste de los precios ante variaciones del conjunto de la producción disponible en dos momentos temporales distintos (presente y futuro). De hecho, en una economía no estacionaria y, por tanto, con variaciones de productividad, la estabilización de la renta nominal implicaría necesariamente variaciones de los precios que reflejen la evolución de la oferta de bienes y servicios disponibles en el mercado a lo largo del tiempo.

$$
\begin{gathered}
\dot{M}_{t}^{S}=\left(\Pi^{*}+\dot{T}_{r}^{e}-\dot{V}^{e}\right)_{t}=\left(\dot{T}_{\text {nom }}^{e}-\dot{V}^{e}\right)_{t} \Leftrightarrow \Pi_{t}^{*} \neq 0 \\
\left\{\begin{array}{l}
\text { Si } \Delta \text { Productividad } \Rightarrow \Delta \dot{T}_{r} ; \nabla \Pi \Leftrightarrow \dot{T}_{\text {nom }} \text { constante } \\
\text { Si } \nabla \text { Productividad } \Rightarrow \nabla \dot{T}_{r} ; \Delta \Pi \Leftrightarrow \dot{T}_{\text {nom }} \text { constante }
\end{array}\right.
\end{gathered}
$$

Con la aplicación de una mejora tecnológica se registrará un aumento de la productividad que conducirá, a través de su desarrollo y progresiva adaptación al proceso productivo, a un aumento de la oferta de los bienes y servicios finales disponibles. Ante tal expectativa, resultará beneficiosa, tanto para el empresario como para el asalariado, una situación en la que los precios puedan ajustarse a la baja (al alza) ante un incremento (disminución) de la oferta productiva.

Para el productor, una mejora de la productividad se reflejará en una mayor capacidad para ofrecer su producción al mercado, dado que soporta unos costes de producción ahora más reducidos. En los mercados donde mayor sea la existencia de rivalidad entre distintos oferentes en la provisión de un bien, la propia competencia del mercado hará que la demanda sea muy sensible a variaciones del precio. En este tipo de mercados, con elasticidad-precio elevada $\left(\mathrm{E}_{\mathrm{P}}>1\right)$, el productor que logre aumentar su oferta sin aumentar sus costes podrá reducir el precio de venta y, con ello, aumentar su volumen de fac- 
turación y beneficio más que proporcionalmente. Asimismo (Selgin, 1997), estos ajustes de los precios ante variaciones de la productividad son posibles dentro de modelos de explicación de la formación de precios que suponen cierta rigidez de algunos componentes de los costes a corto plazo, como el salario. Por tanto, en la medida en que el productor consiga reducir sus costes en mercados abiertos, tendrá incentivos para reducir el precio de venta de su producción y, por tanto, ganar cuota de mercado, sin ver por ello reducidos sus beneficios (Selgin, 1999).

Para los asalariados, el aumento de la productividad asociado a descensos de los precios producirá aumentos paralelos de su salario real. Asimismo, en caso de imposibilidad de revisión instantánea del salario del trabajador ante variaciones de su productividad, tal aumento del poder adquisitivo de su salario se convierte en un método eficaz para beneficiar a los trabajadores con mayor capacidad productiva. Con ello se conseguiría un sistema de actualización automática del salario real de los trabajadores a la evolución real de su productividad.

Por tanto, es una política de emisión de liquidez concordante no sólo con la hipótesis de rigidez de algunos costes (y, en concreto, de los salarios) a corto plazo, sino también con la hipótesis de ausencia de ilusión monetaria de los agentes (esto es, agentes que son capaces de percibir y anticipar los efectos de las medidas monetarias sobre la capacidad adquisitiva real de sus rentas); de modo que, en ausencia de cambios en la regla monetaria, la planificación de sus decisiones y la valoración de la situación económica se realiza sobre la base de cálculos de variables medidas en términos reales. 


\section{Crítica teórica al objetivo de estabilización de precios: variaciones de productividad y formación de expectativas de precios}

Aun en este contexto de ausencia de ilusión monetaria, habrá situaciones en que los agentes no interpreten correctamente los cambios de oferta y de demanda producidos en el entorno de su actividad cotidiana, dado que su origen puede situarse fuera del propio medio que le rodea. Estudiaremos a continuación cómo son interpretadas y percibidas las variaciones de los precios en un contexto monetario dirigido por una regla monetaria basada en la estabilización de la renta nominal.

Selgin (1997) señala dos tipos de circunstancias que pueden provocar, si bien en grado y probabilidad muy distinta, una falta de reacción o bien una incorrecta adaptación de los agentes ante variaciones percibidas en el índice general de los precios de una economía; lo que, en ambos casos, generaría pérdidas agregadas por una incorrecta asignación de los recursos disponibles y una reducción de las posibilidades de crecimiento de la economía a largo plazo. Dependiendo del origen de los cambios producidos en los precios, podemos distinguir dos grandes $\operatorname{casos}^{21}$ : por un lado, las variaciones debidas a cambios generales o particulares de la productividad que provocan variaciones en la oferta de bienes y servicios (shock real, endógeno, ya sea general o específico), y, por otro lado, las variaciones debidas a cambios en la cantidad de liquidez en circulación que provocan variaciones de la demanda de bienes y servicios (shock monetario, exógeno).

${ }^{21}$ Hayek (1928) distingue entre variaciones del índice general de precios que tienen su origen en el «frente de los bienes» y aquellas que tienen su origen en el «frente del dinero» (p. 160). En este trabajo calificaremos a las primeras como «shocks reales», debidos a cambios de la productividad, y a las segundas como «shocks monetarios», debidos a cambios en la cantidad de liquidez en circulación. 
En primer lugar, en relación con una variación de la productividad, podemos distinguir, a su vez, dos casos teóricos posibles:

Si es una variación específica de la productividad de una empresa o un sector, sus efectos serán más fácilmente anticipables por los agentes, ya que son ellos mismos, o bien las empresas de su mercado particular, quienes han desarrollado una innovación que ha conseguido aumentar sus tasas de productividad; reflejándose al final en los precios el resultado pretendido inicialmente. Por tanto, los ajustes en los precios particulares o sectoriales derivados, respectivamente, de variaciones específicas o sectoriales de la productividad, son fácilmente previsibles por los agentes, dado que son el producto de una planificación previa que conduce a un resultado deseado; por lo que están exentos de los problemas de identificación asociados a los shocks de demanda (Hayek, 1928). En este sentido, el empresario del sector correspondiente, ya sea porque es quien protagoniza la innovación, ya sea porque observa los métodos productivos desarrollados por la competencia, tiene información generada en el propio mercado como para poder interpretar correctamente la evolución previsible de los precios.

Si es una variación general de la productividad, debida a la difusión de una innovación que afecta a todos los sectores productivos, los agentes no tienen información suficiente para interpretar su origen $y$, por tanto, para poder anticiparlos correctamente. Sin embargo, en la medida en que se desarrolle una regla de emisión que permita el reflejo en los precios de un cambio generalizado en la productividad, los agentes percibirán en poco tiempo sus efectos sobre los precios. En este contexto, en una economía en crecimiento, la observación recurrente de reducciones del índice general de precios podrá aportar información relevante que nos permita inferir la evolución favorable de la productividad. Por tanto, las variaciones del índice general de precios, lejos de ser una fuente de error en la pla- 
nificación de las decisiones de los agentes, permite la obtención de información útil ${ }^{22}$ para interpretar la evolución de las condiciones productivas de una economía dinámica (Hayek, 1928; Selgin, 1997).

Ahora bien, difícilmente podemos caracterizar los procesos de innovación y variación de la productividad como procesos generales y homogéneos entre los distintos sectores y unidades productivas de la economía (Hayek, 1928). Por el contrario, resulta más realista suponer que son las empresas las que, individual y arriesgadamente, a partir del conocimiento específico del mercado concreto en que ejercen su actividad, invierten los recursos necesarios para aumentar su capacidad productiva en el futuro. En este sentido, consideramos más realista suponer que la disminución de los costes y precios son el resultado previsto del aumento de la productividad generados en una empresa o sector. Como consecuencia de ello, la reducción de los precios asociada a aumentos de la productividad, lejos de ser una fuente de generación de decisiones erróneas por parte de los agentes, será más bien el resultado lógico y previsible de un largo proceso de planificación empresarial de su actividad productiva ${ }^{23}$.

En segundo lugar, en relación con una variación de los precios causada por variaciones de la oferta de liquidez en circu-

22 «[ante variaciones generales de la oferta de la economía] Puede hacer falta también que existan diferencias en todos o en la mayoría de los precios que prevalecen en distintos puntos del tiempo, y por eso los movimientos del llamado "índice general de precios" cumplen una función definida. No es pues necesario dedicar demasiado espacio a esa ingenua concepción de la "teoría cuantitativa" que estipula que el único fundamento para negar la necesidad de variaciones en el nivel de los precios procede del frente de los bienes» (Hayek, 1928, p. 148).

"[...] El "valor del dinero" no puede permanecer inalterado cuando la situación del mercado varía, sino que debería estar ajustándose continuamente a estas condiciones variables» (Hayek, 1928, p. 159).

23 Por este motivo, Selgin (1997) señala que, en ausencia de una medida monetaria expansiva, esta mejora de la productividad sectorial se reflejará en menores precios en dicho sector $y$, proporcionalmente a su peso en la economía, en un menor valor del índice general de precios (pp. 31-32). 
lación, los productores ahora no tienen, al menos durante cierto periodo de tiempo, información suficiente para poder diferenciar cuál es el origen de la variación imprevista de la demanda (shock de demanda) y, por tanto, para poder evaluar si es una variación específica o general. De hecho, esta variación de la demanda es de naturaleza necesariamente exógena al mercado, dado que surge como consecuencia de una decisión monetaria tomada a partir de circunstancias ajenas a las que rodean las acciones de los agentes. Por ello, en tanto que variaciones surgidas al margen de los procesos de cálculo y planificación de las decisiones de los productores y consumidores, generan incertidumbre y, con ello, la necesidad de interpretar sus causas y consecuencias más previsibles.

En este sentido, en el caso de que el productor interprete la variación de la demanda como un fenómeno particular o específico de su empresa o sector, ello indicaría una variación real de las preferencias de los usuarios hacia una determinada empresa o sector; mientras que, en el caso de interpretarla como un fenómeno general, la variación de la demanda no sería más que el reflejo de una variación general de la demanda nominal de bienes y servicios, como mero resultado de la alteración de las condiciones monetarias ${ }^{24}$.

Dado que un shock de demanda generado por una medida de política monetaria provoca una variación de los precios que no tiene su origen en el propio mercado donde actúan los agentes, esta fuente de variación de los precios puede tener efectos reales sobre la evolución de actividad, a través de la propia

24 Las consecuencias derivadas de una u otra interpretación son bien distintas en relación con la planificación de la producción empresarial. En el primer caso, el empresario interpretaría un aumento específico de su demanda, por lo que intentaría adaptar su capacidad productiva para poder abastecer a una demanda en aumento. En el segundo caso, su demanda permanecería igual en términos relativos a la del resto de empresas, por lo que, no aumentaría su capacidad productiva en el futuro por este motivo. 
naturaleza del proceso de ajuste ${ }^{25}$ de los agentes a la nueva situación. Asimismo, estos efectos no siempre son perceptibles a través del análisis agregado de los precios, generándose así una política monetaria realmente no neutral ${ }^{26}$ (Yeager, 1986) que sí afecta a la configuración de la estructura productiva de la economía. Por tanto, y en contra de lo que supondría la interpretación extrema del paradigma de racionalidad neoclásico asociado a la Hipótesis de Expectativas Racionales (HER) (Lucas, 1972), no consideraremos realista el ajuste total e instantáneo de las decisiones de los agentes a los cambios percibidos de demanda, a partir de un conjunto de información dado y eficientemente utilizado ${ }^{27}$; en su lugar, supondremos que los agentes reaccionarán a las nuevas condiciones del mercado a través de un proceso de ajuste costoso y discontinuo que requiere la

25 En referencia al modo en que tiene lugar el ajuste de las decisiones individuales a la nueva demanda percibida, Yeager (1986) resalta cómo la incertidumbre a la que se enfrentan los agentes, la rigidez de los precios y salarios a corto plazo, así como la propia naturaleza de la información disponible en el mercado son las causas que permiten la generación de efectos reales sobre la producción o el empleo: "It is illegitimate to suposse that people somehow just know about monetary disequilibrium, know what preassures it is tending to exert for corrective adjustments in prices and wages generally, and promptly use this knowledge in their own pricing decisions. [...] Bussinessmen do not have a quick and easy shortcut to the results of the market process. [...] Money-supply numbers are far from everything they need to know for their business decisions» (pp. 374-375).

26 Dentro del cuerpo teórico de la economía neoclásica, una política monetaria se considera neutral cuando la alteración de las condiciones de crédito de la economía no tiene efectos perdurables sobre la actividad y el empleo, sino tan sólo sobre el nivel general de precios. Con ello, no se está considerando los efectos reales que sí están teniendo lugar en la estructura productiva del mercado. Por ello, el objetivo de la regla monetaria no debe ser la persecución de un resultado agregado inalterado en términos de renta y empleo, sino la no distorsión de las condiciones productivas de la economía.

27 Respecto al significado y validez de la HER, Yeager (1986) denomina esta hipótesis como propia de la teoría del equilibrio perpetuo (equilibrium-always theory), dado que está diseñada para garantizar, ante cualquier shock, un ajuste perfecto e instantáneo de los agentes que garantiza la vuelta a la senda de equilibrio a largo plazo de la economía. Por tanto, es una teoría diseñada para explicar comportamientos que conduzcan a situaciones de equilibrio o de coordinación social plena (pp. 386-395). 
obtención y uso de un conjunto de información parcial y diverso, conjunto que únicamente es trasmitido a través de la propia dinámica descentralizada de múltiples decisiones particulares de los agentes que interactúan en el mercado (Hayek, 1928; Huerta de Soto, 1992; Kirzner, 1992).

En este sentido, si bien transcurrido un cierto periodo de tiempo, una variación de la oferta de liquidez se trasladará en una variación del índice general de los precios de consumo, siendo, por tanto, una medida no generadora de mayor actividad y empleo a largo plazo, la relación y el peso de cada uno de los precios individuales que integran el índice general habrá cambiado en la medida en que lo hayan hecho las decisiones de los agentes. Por tanto, sólo podrán permanecer inalterados los precios relativos y la estructura interna de los procesos productivos si el shock monetario afectara a todos los agentes por igual y éstos, manteniendo su conjunto de preferencias inalterado, trasladaran la variación de la oferta monetaria detectada en variaciones proporcionales de los precios. Dado que el cauce de distribución del shock monetario difiere en la realidad de esta situación tan excepcional, la utilización de un análisis agregado basado en la aplicación de la Ecuación Cuantitativa del Dinero, nos conducirá a una situación de equilibrio agregado alcanzado tras el ajuste de los precios a la nueva liquidez en circulación (20). Pero, con ello, no estaremos analizando el modo en que la variación de la oferta monetaria ha alterado, de manera desigual e inesperada, la demanda percibida por los productores en cada mercado y, con ello, los precios relativos dentro de cada mercado, así como entre cada uno de ellos (Mises, 1912; Hayek, 1932). 
Ecuación Cuantitativa: $\dot{M}_{t}^{S}+\dot{V}_{t}+\Pi_{t}+\dot{T}_{r, t}$

Si $\Delta \dot{M}^{S} \Rightarrow \dot{M}_{t+1}^{S}+\dot{V}_{t}>\Pi_{t}+\dot{T}_{r, t} \Rightarrow \dot{M}_{t+1}^{S}>\dot{M}_{t}^{D}$

Ajuste ¿neutral?: $\dot{M}_{t+1}^{S}+\dot{V}_{t}=\Pi_{t+1}+\dot{T}_{r, t} \Leftrightarrow \dot{M}_{t+1}^{S}=\dot{M}_{t+1}^{D}$

Siendo: $\Pi_{t+1}>\Pi_{t}$

Asimismo, si la variación de la oferta de liquidez se debe a la consecución de un objetivo del banco central consistente en reestablecer el equilibrio monetario y, por tanto, la estabilidad de precios, como pretendida vía para no generar distorsiones en los mercados de bienes y servicios, el proceso de ajuste de los precios no sólo alterará los precios relativos entre distintos mercados, sino que también eliminará la función informativa del índice general de precios, como señal indicativa de la evolución de los costes de producción en una economía no estacionaria (Hayek, 1928).

\section{Reformulación de la regla de productividad de Hayek}

De acuerdo con F.A. v. Hayek, uno de los exponentes más representativo de la conocida como Teoría Austriaca del Ciclo Económico ${ }^{28}$, son precisamente los ajustes al alza de la cantidad de dinero en circulación, en respuesta a aumentos de la productividad, la causa principal de los errores de cálculo de los empresarios $\mathrm{y}$, por tanto, del desarrollo de procesos de sobreinversión que se manifestarán, con el paso del tiempo, equivocados e irrealizables; siendo entonces inevitable una desinversión que provocará, finalmente, ajustes laborales y productivos. En concre-

28 Puede consultarse los trabajos de Haberler (1986), Huerta de Soto (1998) (Caps. V y VI) y Feito (1999) para una exposición más profunda y detallada de la Teoría Austriaca del Ciclo Económico, así como el trabajo de Bordo (1986), donde aparece de manera muy sintética una presentación de las principales críticas planteadas a esta teoría del ciclo. 
to, si se produce una mejora tecnológica en un sector, ello permitirá, una vez aplicada al proceso productivo, un aumento de la capacidad productiva; por lo que los empresarios esperarán poder producir en el futuro una mayor cantidad de bienes o servicios a menores costes $(\mathrm{C}) \mathrm{y}$, por tanto, a un menor precio (21a). Por su parte, los demandantes tenderán a postergar la satisfacción de su demanda hasta el momento en que tal proceso de descenso del precio de venta sea efectivo. Por tanto, los efectos previsibles de la aplicación de la mejora productiva serán la consecución de un mercado en equilibrio en el futuro, con una mayor cantidad ofrecida, una mayor cantidad demandada y a un menor precio.

Si $\Delta$ Productividad $\Rightarrow C_{t}>C_{t+1} \Leftrightarrow P_{t}>P_{t+1}^{E}$ $P_{r}=\frac{P_{t+1}^{E}}{P_{t}}$

Sin embargo, si una vez realizada la expectativa del productor de un aumento de su capacidad productiva a menores precios en el futuro, el banco central contrarresta la tendencia deflacionista de una economía en crecimiento con aumentos paralelos de la oferta de medios de pago, a medida que sean percibidos los efectos del exceso de liquidez, los productores realizarán una nueva expectativa de precios, ahora inflacionista, que variará las condiciones del mercado que provocaron inicialmente la inversión empresarial (21b): Por un lado, ante el aumento esperado de los precios de venta de la producción en el futuro, dada la capacidad de producir a menores costes, el productor percibe un estímulo añadido a su proceso de inversión (no sostenido en ninguna causa real), consistente en el mayor ingreso esperado de la venta de su producción en el futuro, por lo que tiene incentivos para aumentar aún más su capacidad productiva [ya que el valor esperado de la producción en el futuro ha aumentado en relación con su valor actual $\left.\left(\Delta \mathrm{P}_{\mathrm{r}}\right)\right]$. 
Ahora bien, por otro lado, el exceso de liquidez derivado de la medida monetaria tomada producirá un exceso de demanda de bienes en el momento actual (un adelantamiento de la decisión de consumo), hecho que aumentará la demanda y el precio de la producción actual ${ }^{29}$ antes de que pueda materializarse la mejora de la capacidad productiva del sector correspondiente. En este momento, dada la sobreinversión realizada por el empresario, éste no tendrá recursos para atender a una demanda de consumo actual creciente; por lo que se manifestará una escasez de la oferta, que aumentará aún más el valor relativo de la producción actual en relación con la futura. A partir de este momento, se irá reduciendo la rentabilidad relativa de la inversión en curso, a medida que el productor tenga que soportar crecientes costes de producción a corto plazo para poder atender a una demanda actual creciente; por lo que, progresivamente, le será más costoso mantener el gran número recursos empleados para el aumento de su capacidad productiva en el futuro.

Si $\Delta M^{S}$ :

$$
\Delta P_{t+1}^{E} \Rightarrow \Delta P_{r}=\Delta \text { Inversión }
$$

A partir de esta exposición, Hayek (1928) propone el establecimiento de un criterio de emisión para el banco central ${ }^{30}$

29 Resulta fundamental en esta explicación observar que el aumento de los precios registrados en el presente repercute en las decisiones del empresario antes de que pueda completar su proceso de inversión y, por tanto, antes de que pueda realizar su expectativa de aumento de su oferta productiva con un mayor precio de venta.

30 Paralelamente, dado que Hayek pretende con esta propuesta mantener constante la cantidad de liquidez en circulación en una economía en crecimiento, se supone que ha de limitarse la capacidad de creación de medios de pago (dinero interno) del resto de entidades financieras. Ello se conseguiría, a partir de las propuestas tradicionales de la Escuela Austriaca de Economía (Mises, 1912), eliminando 
que no persiga el equilibrio monetario instantáneo, ni, por tanto, la estabilidad de precios en todo momento, tal y como defienden los teóricos monetaristas, sino un criterio de emisión que permita lo que denominó como el «equilibrio intertemporal de los precios», mediante variaciones de los precios que reflejen, a su vez, las variaciones de los costes relativos a lo largo del tiempo en los distintos procesos productivos.

La adopción de este criterio de emisión permitiría al banco central generar una respuesta monetaria diferenciada en función del origen de la variación de los precios prevista. En concreto, si se estima que la variación de los precios es una consecuencia lógica de la variación de la productividad de la economía, el banco central podrá fijar un valor objetivo de la renta nominal constante que considere tal posibilidad; por lo que no reaccionará ante este cambio de las condiciones productivas, dado que el aumento de la producción real se ve compensado en este caso por una reducción de los precios. Ahora bien, si se estima que la variación del precio se debe a una variación de la demanda, el banco central podrá intervenir para corregir la desviación esperada de la renta nominal respecto a su valor objetivo a largo plazo. De este modo, en el caso de preverse un shock expansivo de demanda, generado por una expansión de la política fiscal, o bien, por una evolución favorable del mercado exterior, aumentará el valor de la renta nominal a corto plazo, ante lo que el banco central podrá reaccionar reduciendo gradualmente el volumen de medios de pago en circulación.

Por tanto, el establecimiento de un criterio de emisión que vincule la evolución de la liquidez a la de la renta nominal per-

la posibilidad de emitir dinero bancario a partir de los depósitos recibidos de sus clientes; esto es, estableciendo un coeficiente de caja del 100\% de los depósitos. De hecho, en ausencia de esta condición, la reforma de la política monetaria planteada por Hayek tan sólo limitaría la emisión de un tipo de medio de pago (el dinero del banco central), si bien, como sabemos, condicionaría de manera importante, la política de emisión del resto de entidades financieras. 
mite una difusión de la información generada en el mercado y, como consecuencia de ello, una mayor facilidad de adaptación de los agentes a los cambios percibidos en los procesos productivos. Así, el banco central estaría creando unas condiciones monetarias de las que pueden derivarse mejoras en la asignación de los recursos, mediante la creación de un entorno monetario estable que facilita el cálculo económico y la planificación de las acciones de los agentes.

\section{a) Regla de productividad generalizada}

Adoptando el criterio de emisión originalmente presentado por Hayek (1928), planteamos finalmente una reformulación de su regla de emisión que, partiendo de la consecución del objetivo de estabilización de un indicador de la renta nominal, tenga en cuenta el distinto grado en que las variaciones de productividad se transmiten en los precios finales dependiendo de la estructura de competencia de los mercados de bienes y servicios.

Hemos visto que el argumento de Hayek (1928) conduce a la propuesta de una regla de estabilización de la renta nominal consistente con los objetivos de emisión del banco central como entidad de naturaleza financiera; a saber, el aumento de las ganancias de señoreaje a largo plazo, la contribución a la eliminación de las fluctuaciones causadas por la introducción de shocks monetarios dirigidos a estabilizar los precios y, por último, el desarrollo pleno del proceso de mercado como medio para transmitir información valiosa y útil para la toma de decisiones de los agentes. Ahora bien, la idoneidad de este criterio de emisión mantenido por Hayek descansa implícitamente en el cumplimiento de una hipótesis teórica previa; a saber, la existencia de un margen de competencia en el mercado suficiente ${ }^{31}$

31 A diferencia de Hayek, Selgin (1997) introduce en su análisis explícitamente el supuesto de mercados de producto con elasticidad-precio unitaria. De este 
como para provocar que el empresario con ganancias de productividad tenga incentivos para repercutir en gran medida el descenso de costes conseguido en sus precios de venta. Con ello, Hayek estaría planteando la regla de emisión del banco central en un horizonte temporal largo, a partir del cual los mercados pueden considerarse potencialmente abiertos a la competencia ${ }^{32}$.

Sin embargo, a la vista de las condiciones del mercado, si lo que queremos es plantear una pauta de emisión operativa para el banco central, se han de considerar escenarios de largo plazo no totalmente competitivos, así como la existencia de mercados oligopolísticos y monopolísticos como una realidad empírica a corto plazo que, necesariamente, nos aleja de la utilización del supuesto único de demanda elástica, como vía teórica para prescribir la traslación total de las variaciones de los costes en los precios de venta del producto.

Por tanto, como hipótesis general, mantendremos en su lugar la existencia de un cierto grado de ajuste de los precios finales ante variaciones de la productividad, que dependerá de la estructura de la competencia vigente en el mercado en cada momento determinado. Por ello, propondremos una regla monetaria que establezca la consecución de un objetivo de renta nominal a largo plazo, si bien resulte compatible con un objetivo implícito de variación de los precios, que sea el resultante de la estructura de la competencia del mercado y, por tanto, de la traslación esperada de las variaciones de la productividad en los precios finales.

De modo que, si se genera una innovación en una empresa de un mercado muy competitivo, al propio empresario le resul-

modo, el descenso de precios resultante de un aumento de la productividad no repercute de ninguna manera sobre el volumen de beneficios del empresario.

32 De este modo, podemos entender la regla de emisión propuesta por Hayek como una regla válida dentro de un marco dinámico, que considera los efectos de las medidas monetarias a largo plazo, en un horizonte de tiempo donde pueden suponerse ausentes las barreras técnicas de entrada al mercado. 
tará rentable bajar precios con el fin de aumentar su cuota de mercado más que proporcionalmente y, con ello, su volumen de beneficios. Por tanto, en este caso concreto, que coincide con el supuesto manejado originalmente por Hayek, el aumento de la productividad resultante de la innovación se reflejará en un descenso de precios. Ahora bien, a medida que nos situemos en mercados menos abiertos a la competencia, donde ya sea por la existencia de barreras de entrada, ya sea por pactos implícitos entre los productores, la competencia se centre en variables distintas al precio y los productores tengan cierto poder de mercado, los aumentos de productividad repercutirán crecientemente en un aumento del margen $(\mathrm{m})^{33}$ de beneficio del productor $y$, por tanto, decrecientemente en bajadas del precio de venta.

Por tanto, plantearemos el objetivo de la regla de emisión como un objetivo compatible con la obtención de las ganancias de señoreaje a largo plazo y, por tanto, con una evolución cíclica realmente estable; lo que, como hemos comprobado, requerirá variaciones de precios ante variaciones de las condiciones productivas (C), si bien teniendo en cuenta la estructura de la competencia en el mercado en cada momento (representada a través del valor de la elasticidad-precio, « $\left.\mathrm{E}_{\mathrm{P}} »\right)(22$ y 23). Así, dependiendo de la estructura del mercado existente, una misma variación de la productividad tendrá distintos efectos sobre la evolución de los precios a corto plazo $\left(\mathrm{P}_{c p}\right)$ :

$$
\begin{aligned}
& \mathrm{P}_{c p}= f(C, m) \\
& \mathrm{P}_{c p}=C+\bar{m} \Leftrightarrow \text { si } \mathrm{E}_{P} \geq 1 ; \bar{m} \text { constante } \\
& \mathrm{P}_{c p}=C+m(C) \Leftrightarrow s i \mathrm{E}_{P}<1 ; m^{\prime}(C)<0
\end{aligned}
$$

33 Dado que Selgin (1997) desarrolla su argumento en un mercado competitivo, mantiene que este margen de beneficio del empresario es constante a pesar del aumento de la productividad, por lo que el empresario aplicará el mismo margen sobre una cantidad vendida mayor, a un menor precio (22). 
- En mercados con elasticidad-precio elevada (22), las variaciones de productividad se reflejarán fundamentalmente en variaciones de los precios, dado que los productores no tienen poder suficiente como para modificar el margen de beneficios ( $\bar{m}$ constante). Por ello, en presencia de mercados abiertos, un banco central estabilizador de la renta nominal preverá una disminución de los precios ante aumentos esperados de la productividad.

- En mercados con elasticidad-precio reducida (23), los productores tendrán cierta capacidad para la modificación de su margen de beneficio ante variaciones de la productividad ( $m$ variable). Por ello, el banco central preverá, tan sólo, un ajuste parcial de los precios a la baja ante aumentos esperados de la productividad o, incluso, ningún grado de ajuste a la baja.

Para reflejar los distintos objetivos que adoptará el banco central en presencia de distintos tipos de estructura de mercado, podemos sintetizar las distintas funciones de reacción que puede adoptar el banco central a partir de la propuesta de una expresión alternativa y generalizada (24) de la regla de productividad; expresión que establece un objetivo de renta nominal a largo plazo, que permite considerar implícitamente un objetivo de inflación nula, como un caso particular que se corresponde con un supuesto particular sobre la formación y evolución de los precios. 
b) Función de reacción generalizada ${ }^{34}$

$$
\begin{aligned}
& \dot{\mathrm{M}}_{t}^{S}=\left(\dot{\mathrm{Y}}_{r, t+i}^{*}+\lambda_{1} \dot{\mathrm{Y}}_{r, t+i}^{*}\right)^{e}-\dot{V}_{T, t+i}^{e}+\lambda_{2}\left(\dot{\mathrm{Y}}_{n o m, t+i}^{*}-\left(\dot{\mathrm{Y}}_{n o m, t+j}\right)^{e}\right) \\
& \lambda_{1} \dot{\mathrm{Y}}_{r, t+i}^{*}=\Pi^{*} \Rightarrow \lambda_{1}=\frac{\Pi^{*}}{\dot{\mathrm{Y}}_{r, t+i}^{*}}
\end{aligned}
$$

Siendo: $\mathrm{j}<\mathrm{i}$

- $\dot{\mathrm{M}}_{t}^{S}$; un agregado monetario amplio que incluye, tanto el dinero emitido por el banco central, como el conjunto de pasivos líquidos emitidos por las entidades financieras del área monetaria correspondiente.

- $\dot{\mathrm{Y}}_{n o m, t+i}^{*}=\left(\dot{\mathrm{Y}}_{r, t+i}^{*}+\lambda_{1} \dot{Y}_{r, t+i}^{*}\right)^{e} ;$ la tasa de variación objetivo de la renta nominal a medio o largo plazo.

- $\left(\dot{\mathrm{Y}}_{n o m, t+j}\right)^{e}=\mathrm{E}\left(\dot{\mathrm{Y}}_{n o m, t+j}\right)_{t} ;$ la tasa de variación prevista de la renta nominal «j» trimestres hacia delante, a partir de la información manejada hasta el periodo «t», correspondiente al periodo de toma de la decisión monetaria.

- $\dot{V}_{T, t+i}^{e} ;$ la tasa de variación prevista de la velocidad de circulación del dinero a medio o largo plazo.

- $\lambda_{1}$; el coeficiente indicativo del grado de estabilización de los precios ante variaciones de la productividad de la economía, caracterizador del objetivo de precios implícitamente mantenido por el banco central a largo plazo y, asimismo, de la adaptación esperada de los precios a las variaciones de la productividad de la economía. Por tanto, en el caso de

34 Tal y como se detalla en Castañeda (2003) y Castañeda y Schwartz (2004), esta expresión de la función de reacción puede interpretarse como una generalización de la propuesta en 1987 por B. McCallum, dado que permite la adopción de distintos objetivos de precios en función de la variación de la productividad y su traslación esperada en los precios finales. Por ello, la hemos denominado igualmente en dichos trabajos como la regla de renta nominal generalizada. 
que el banco central adopte un objetivo de estabilización de la renta nominal a largo plazo, su valor dependerá de las características de la economía correspondiente y, en concreto, de la estructura de la competencia esperada en los mercados de bienes y servicios donde se desarrolle la regla monetaria; si bien, sí podemos señalar algunos factores generales que determinarán su valor:

- El grado de apertura exterior de la economía.

- El grado de apertura interna del mercado; esto es, el entorno legal que regula el acceso a los mercados de nuevos competidores en el futuro.

- $\lambda_{2}$; el coeficiente de reacción del banco central ante desviaciones esperadas de la renta nominal a corto plazo $(« t+j »)$ respecto al valor objetivo a medio y largo plazo $(« t+i »)$. De nuevo, dependiendo del valor dado a este parámetro, tendremos una función de reacción que permite distintos grados de intervención del banco central en el mercado monetario.

\section{CONCLUSIONES}

La actualización que hemos realizado de la propuesta monetaria presentada por Hayek en 1928 nos permite identificar algunas implicaciones de Economía Política relevantes para la mejora de una de las principales instituciones de una economía de mercado. De hecho, su propuesta de estabilización de renta nominal no debe ser evaluada de manera aislada. Precisamente, el análisis teórico que sustenta la regla de emisión defendida por Hayek devuelve el marco de análisis de la política monetaria al estudio de la formación y evolución de los precios relativos en los mercados de bienes y servicios. Con ello, en nuestra opinión, fenómenos como el análisis del modo en que los empresarios forman sus expectativas de precios, como 
consecuencia de su observación de la evolución de las condiciones productivas y la propia estructura de los mercados de bienes finales y de capital, deben ser considerados como relevantes a la hora de establecer las bases de una política monetaria verdaderamente neutral y estable en el medio y largo plazo; esto es, una política que no distorsione los procesos de formación de expectativas y precios que, de forma natural e interesada, desarrollan los agentes del mercado.

Por ello, partiendo de las bases teóricas dadas por Hayek, hemos propuesto una pauta de variación de la liquidez que tiende a situar al banco central crecientemente en un entorno de mercado y, con ello, sujeto a los controles propios de los demandantes de sus servicios. Alejados del concepto de equilibrio instantáneo utilizado por los teóricos monetaristas, el desarrollo de una regla de emisión consistente en la estabilización de la renta nominal permite las lógicas variaciones de precios derivadas de cambios en las condiciones productivas, en presencia de mercados potencialmente abiertos.

Como consecuencia de la adopción de este criterio de emisión, los modelos macroeconómicos habitualmente utilizados para interpretar la realidad y, con ello, la preeminencia única del objetivo de estabilidad de precios, quedan reemplazados por modelos de análisis que permiten variaciones de precios como consecuencia necesaria de la traslación de las condiciones productivas a lo largo del tiempo. De hecho, son precisamente estas variaciones de precios las que permiten una evolución estable de los procesos de mercado. Por ello, dentro del análisis que hemos realizado, la estabilidad monetaria y el correcto funcionamiento del sistema de precios pasan a ser objetivos propios del banco central. 


\section{BIBLIOGRAFÍA}

Bagehot, W. (1873), Lombard Street. A Description of the Money Market. Ed. John Wiley \& Sons, Inc., Londres (1999).

Black, S.W. (1992), «Seignioraje», en The New Palgrave Dictionary of Money and Finance, vol. III. Ed. Newman, P.; Milgate, M. y Eatwell, J. Macmillan, Londres, pp. 438-439.

Bordo, M.D. (1986), «Austrian Influence on Business Cycle Theory», en Cato Journal, vol. 6, n. 2 (otoño), pp. 455459.

Boskin, M.; Dulberger, E.; Gordon, E.; Griliches, Z. y JorgenSON, D. (1996), «Toward a More Accurate Measure of the Cost of Living». Final Report, Senate Finance Committee.

Castañeda, J. (2003), Propuesta de una regla de emisión para el Banco Central Europeo. De la estabilidad de precios a la estabilidad monetaria. Tesis doctoral, Universidad Autónoma de Madrid (junio). Dir.: P. Schwartz.

CAstañeda, J. y Schwartz, P. (2001), «Análisis de las funciones del Banco Central Europeo en un entorno de libre concurrencia y convertibilidad». Trabajo presentado en la III Reunión de Economía Mundial, San Pablo-CEU, Madrid, 19 de abril de 2001.

- (2004), Propuesta de una regla monetaria alternativa: Especificación de la función de reacción generalizada. (Pendiente de publicación).

Dowd, K. (1998), «Monetary Policy in the $21^{\text {st }}$ Century: An Impossible Task?», en Cato Journal, vol. 17, n. ${ }^{\circ} 3$ (invierno), pp. 327-331.

Feito, J.L. (1999), Hayek y Keynes: El debate económico de entreguerras, Ed. Círculo de Empresarios, Madrid.

Fisher, I. (1911), The Purchasing Power of Money. Its Determination and Relation to Credit Interest and Crisis, Ed. A.M. Kelley, Nueva York. Consultada la reimpresión de 1985 de la edición ampliada de 1913. 
Friedman, M. (1956), «The Quantity Theory of Money. A Restatement», en Studies in Quantity Theory of Money. Ed. M. Friedman, University of Chicago Press, Chicago, pp. 3-21.

- (1959), A Program for Monetary Stability, Fordham University Press, Nueva York. Consultada igualmente la edición española: Un programa de estabilidad monetaria y reforma bancaria, Ed. Deusto, Colección de Economía, Bilbao, (1970).

Friedman, M. y Schwartz, A.J. (1963), A Monetary History of the United States (1867-1960), Ed. NBER, Princeton University Press, Princeton (1993).

Goodhart, C. (1988), The Evolution of Central Banks, The MIT Press, Cambridge, Londres.

Haberler, G (1986), «Reflections on Hayek's Business Cycle Theory», en Cato Journal, vol. 6, n. 2 (otoño), pp. 421435.

HAYEK, F.A. v. (1928), «El equilibrio intertemporal de los precios y los movimientos en el valor del dinero», en El nacionalismo monetario y la estabilidad internacional, Ed. Aosta, Madrid (1996), pp. 126-176.

- (1932), La teoría monetaria y el ciclo económico, Ed. Espasa Calpe, Madrid (1936).

- (1978), La desnacionalización del dinero, Ed. Instituto de Economía de Mercado, Unión Editorial, Madrid (1983).

Huerta de Soto, J. (1992), Socialismo, cálculo económico y función empresarial, Unión Editorial, Madrid.

- (1998), Dinero, crédito bancario y ciclos económicos, Unión Editorial, Madrid.

Johnson, H.G. (1968), «Monetary Theory and Policy», en Surveys of Economic Theory. Money, Interest and Welfare, vol. I, Ed. Macmillan, Londres, pp. 1-46.

Jordan, J. y Stevens, E. (1996), «Money in the Twenty-First Century». Working Paper n. ${ }^{\circ}$ 02-96, Ed. Federal Reserve Bank of Cleveland (septiembre). 
KeYNES, J.M. (1923), Breve tratado sobre la reforma monetaria, Fondo de Cultura Económica, Méjico DF (1992).

- (1931), «El fin del patrón oro», en Ensayos de Persuasión, Ed. Crítica, Barcelona (1988), pp. 249-253.

KING, M. (1999), "Challenges for Monetary Policy: New and Old». Trabajo presentado en el ciclo de conferencias titulado New Challenges for Monetary Policy, Federal Reserve Bank of Kansas City (agosto).

KIRZNER, I.M. (1992), The Meaning of Market Process, Ed. Routledge, Londres, Nueva York.

Kydland, F.E. y Prescott, E.C. (1977), «Rules Rather than Discretion: The Inconsistency of Optimal Plans», en Journal of Political Economy, vol. 85, n. 3 (junio), pp. 473-491.

LuCAS, R.E. (1972), «Expectations and the Neutrality of Money», en Journal of Economic Theory, vol. 4, n. 2 (abril), pp. 104-124.

Mayer, T. (1998), Monetary Policy and the Great Inflation in the United States. The Federal Reserve and the Failure of Macroeconomic Policy, 1965-79, Ed. Edgar Elgar, Chentelham. (Reimpresión de 2000).

McCallum, B.T. (1987), "The Case for Rules in the Conduct of Monetary Policy: A Concrete Example», en Federal Reserve Bank of Richmond Economic Review, vol. 73, n. 5 (septiembre-octubre), pp. 10-18.

Menger, C. (1871), Principios de Economía Política, Unión Editorial, Instituto de Economía de Mercado, Madrid (1983).

Mises, L. v. (1912), La Teoría del Dinero y del Crédito, Unión Editorial, Madrid (1997).

Patinkin, D. (1992), «Neutrality of Money», en The New Palgrave Dictionary of Money and Finance, vol. II. Ed. Newman, P.; Milgate, M. y Eatwell, J. Macmillan, Londres, pp. 16-24.

Patinkin, D. y Steiger, O. (1989), «In Search of the Veil of Money and the Neutrality of Money: A Note on the Origin of Terms», en Scandinavian Journal of Economics, vol. 91, n. ${ }^{\circ}$ 1, pp. 131-146. 
Popper, K.R. (1945), La sociedad abierta y sus enemigos, Ed. Paidós, Barcelona (1957).

Selgin, G. (1997), Less than Zero. The Case for a Falling Price Level in a Growing Economy, Ed. Institute of Economic Affairs, Londres.

- (1999), «A Plea for Mild Deflation», en Cato Policy Report, vol. 21, n. ${ }^{\circ} 3$ (mayo-junio), pp. 9-12.

Sмith, V.C. (1936), Fundamentos de la Banca Central y de la libertad bancaria, Unión Editorial, Ediciones Aosta, Madrid (1993).

Svensson, L.E.O. (1998), «Inflation Targeting as a Monetary Policy Rule». Trabajo presentado en Sveriges RiksbankIIES Conference on Monetary Policy Rules (junio). Publicado en Journal of Monetary Economics (1999), n. ${ }^{\circ} 43$, pp. 607654.

TAYlor, J.B. (1993), Macroeconomic Policy in a World Economy. From Econometric Design to Practical Operation, Ed. Norton \& Company, Nueva York, Londres.

- (1998), «Monetary Policy Guidelines for Employment and Inflation Stability», en Inflation, Unemployment, and Monetary Policy, Ed. B. Friedman, The MIT Press, Cambridge, Massachusetts, pp. 29-54.

- (1999), «A Historical Analysis of Monetary Policy Rules», en Monetary Policy Rules, Ed. J.B. Taylor, NBER, Chicago, pp. 319-347.

White, L.H. (1999), The Theory of Monetary Institutions, Ed. Blackwell, Oxford, Massachusetts.

WiCKSELL, K. (1907), «The Influence of the Rate of Interest on Prices», en Economic Journal, vol. 17, n. ${ }^{\circ} 66$ (junio), pp. 213-220. Reproducido en Foundations of Monetary Economics, vol. 2, Ed. D. Laidler, Edgar Elgar, Cheltenham (1999), pp. 1-10.

Yeager, L.B. (1986), "The Significance of Monetary Disequilibrium», en Cato Journal, vol. 6, n. ${ }^{\circ} 2$ (otoño), pp. 369-399. 